\title{
Multi-holes configurations of woven fabric kenaf composite plates: experimental works and 2-D modelling
}

\author{
K. Supar ${ }^{1 *}$ and H. Ahmad ${ }^{1}$ \\ ${ }^{1}$ Faculty of Civil and Environmental Engineering, \\ Universiti Tun Hussein Onn Malaysia, \\ 86400 Parit Raja, Batu Pahat, Johor, MALAYSIA. \\ *Email: khairisupar@gmail.com \\ Phone: +6074564472; Fax: +6074536588
}

\begin{abstract}
A study on structures response in multi-holes plates is important to understand the effect of neighbouring hole on stress concentration as subjected to tensile loading prior to bearing failure in multi-bolted joints. Current work implemented experimental framework on staggered and non-staggered multi-holes configurations to include various lay-up types, plate thickness and hole configurations as specified in the testing series. Experimental observations found that all configurations failed in net-section path suggesting that fracture initiates and propagates from the notch tip perpendicular to loading direction in self-similar fashion through the plate thickness. Non-staggered hole configurations demonstrated peak load compared to staggered counterparts due to more congested holes in staggered configurations. Two-dimensional Extended Finite Element Method (XFEM) modelling framework was carried out in all configurations investigated by sufficient meshing refinements, damage stabilization value and boundary conditions. XFEM was extended from classical finite element expression which has enriched function to enable the crack be tracked visually. A physically-based constitutive model from traction-separation relationship was applied and independently measured material properties and in-plane elastic properties were implemented in current work. Strength prediction results showed that good agreement was found in all testing series and showed discrepancies of less than $15 \%$, the best prediction in combination of PX4 lay-ups and staggered multi-holes configurations series.
\end{abstract}

Keywords: Natural fibres; notched plate; multi-holes; mechanical testing; XFEM.

\section{INTRODUCTION}

Natural fibres have been applied in various engineering sectors and regarded as a sustainable material and free from chemical contaminants. Combination of kenaf fibres as fibre reinforcement to thermoset polymers able to produce a high-performance engineering material with excellent specific strength and elongation at break [1]. In order to assemble different composite parts, joining method are required such as mechanically-fastened joints, adhesively-bonded joints and hybrid bolted-bonded joints, each technique has own advantages and drawbacks. Compared to other joining techniques, bolted joints able to provide parts dismantle for easy inspection and repair, and do not require surface preparations. 
As tensile loading is applied remotely in un-notched plate, the stress profile path held parallel to remote loading direction applied. However, due to existence of plate discontinuities such as open hole, stress concentration reduces its strength capacity. The stress is accumulated at the vicinity of notch edge with a factor of three in isotropic materials, but larger stress concentration value with higher laminate anisotropy. Most works reported in the literatures on open hole problems are limited to single-hole composite plates, the crack initiation occurred ahead of notch tip and subsequently fracture propagation path along net-section plane, and plastic deformation is assumed to be negligible $[2,3,4]$. Cracks at the notch tips provides stress relief and therefore stress concentration is reduced substantially. The notch sensitivity in open hole plate is dependent upon fibre anisotropy, lay-up types, notch geometry, plate thickness, $t$, and hole size $(d / t$ ratio).

There are two main hole configuration exists in bolted joints, i.e., staggered and non-staggered configurations, most structures designers preferred staggered configurations due to ability of the bolts to be compacted within specific area. Subsequently, this is leading to reduction of net-sectional strength of structures plates because of smaller net-sectional area compared to non-staggered holes counterparts. Multi-bolted joints enable by-pass stress to be transferred to the neighbouring bolts compared to single-bolt problem, prone for net-tension failure to occur. In multi-bolts design of composite materials, it is important to study the effect in multi-holes configurations problems to determine joint efficiency in multi-bolts joints during joining design phase. In order to provide efficiency in composite joints, the understanding of stress concentration in open-hole problem should be understood prior to structures joints design phase. However, there are large arrays of variables that affect the strength capacity of multi-holes plate such as hole configurations, lay-up types and plate geometries. Cunningham et al. [5] has carried out series of unidirectional glass fibre reinforced polymer (GFRP) plates on various staggered and non-staggered configuration and found that non-staggered configuration gives higher net-section strength, as expected. In staggered configuration, complex fracture paths exhibited are depending upon gage length, pitch distance and number of staggered hole. There is no research works on multi-hole natural fibre composite plates available in the literatures. Damage path in low-modulus natural fibre may differ from Cunningham's work [3] on multi-hole GFRP plates.

Emerging computing technology enables the material designer to predict the strength of engineering materials by using numerical approaches. A benchmarking work based on experimental framework by Cunningham et al. [5] has been carried out in twodimensional finite element analysis using extended finite element method (XFEM) approach [6]. Reasonably good agreement to experimental results were found, but the fracture energy value used by the respective authors [6] was taken from woven fabric GFRP plates. This may lead to misleading predictions because Cunningham's work is based on unidirectional GFRP. Current works conducted an experimental and 2-D finite element analysis (FEA) framework on multi-hole of WKRP composite plates to include variables such as hole configurations, lay-up types, and plate thickness as specified in the testing series. 2-D FEA frameworks were carried out to determine notched strength of WKRP plates by using independently determined material properties, the strength prediction works are then validated against experimental datasets. 


\section{EXPERIMENTAL FRAMEWORK}

\section{Preparation of Testing Coupons}

Fabrication of WKRP panels were carried out at Fabrications Laboratory, Universiti Tun Hussein Onn Malaysia (UTHM). Kenaf yarn used has a nominal diameter of 0.7 $\mathrm{mm}$ were weaved by using weaving handloom machine to prepare a plain weave architecture layer and combined with epoxy resin (and hardener). Lay-up types used were cross-ply and quasi-isotropic plain weave architectures with nominal thickness of each woven fabric layer is $1 \mathrm{~mm}$. The composite panels were allowed to harden for 24 hours under high pressure and visible voids were inspected. The composites plates were cut into $30 \mathrm{~mm} \times 230 \mathrm{~mm}$ testing coupon including its end tab. $50 \mathrm{~mm}$ end-tab is prepared to avoid slippage during testing. Testing coupons were drilled with $5 \mathrm{~mm}$ diameter circular hole, $d$, care should be taken to ensure there was no hole break-out.

\section{Testing Series and Mechanical Testing}

Testing series were carried out within experimental frameworks consisting of nine multi-hole configurations with various stacking orientations and spacing between adjacent holes. There are four non-staggered and five staggered multi-holes configurations investigated in current study as shown in Figure 1. All testing plates has a constant plate width, $W$ of $30 \mathrm{~mm}$ to avoid plate width effect and gauge length, $L$ of $130 \mathrm{~mm}$.

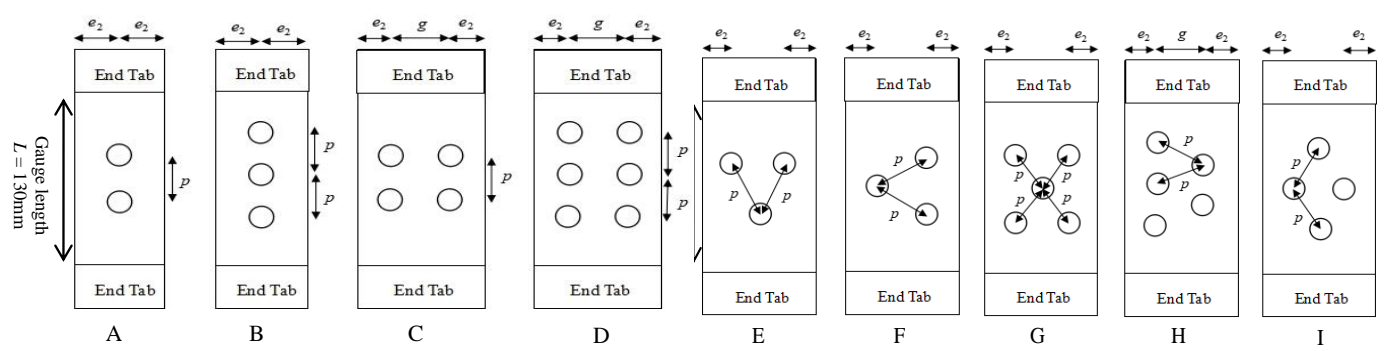

Figure 1. Testing plate geometries of all testing series tested.

Testing series under investigation in current work is given in Table 1, each testing series comprised of three coupons in each lay-up types to give a total of twentyseven coupons for all configurations and notched strength values were obtained by using Equation (1). Notched strength datasets are then validated against finite element analysis frameworks. In current work, a constant value of three in normalised pitch $(p / d)$ and normalised gage length $(\mathrm{g} / \mathrm{d})$ were implemented to assure that notched strength is free from plate geometrical effects.

Table 1. Testing series of experimental frameworks.

\begin{tabular}{cccccccc}
\hline Designation & $\begin{array}{c}\text { Lay-up } \\
\text { types }\end{array}$ & $\begin{array}{c}\text { Plate } \\
\text { thickness, } \\
\boldsymbol{t}(\mathbf{m m})\end{array}$ & Configurations & $\boldsymbol{p} / \boldsymbol{d}$ & $\boldsymbol{g} / \boldsymbol{d}$ & $\begin{array}{c}\boldsymbol{e} / \boldsymbol{d} \\
\boldsymbol{d}\end{array}$ & $\begin{array}{c}\text { Hole } \\
\text { diameter, } \\
\boldsymbol{d}(\mathbf{m m})\end{array}$ \\
\hline $\mathrm{PX} 2$ & $(0 / 90)_{\mathrm{s}}$, & 2 & $\mathrm{~A}, \mathrm{~B}, \mathrm{C}, \mathrm{D}, \mathrm{E}, \mathrm{F}, \mathrm{G}, \mathrm{H}, \mathrm{I}$ & 3 & 3 & 3 & 5 \\
$\mathrm{PX} 4$ & $(0 / 90)_{2 \mathrm{~s}}$, & 4 & $\mathrm{~A}, \mathrm{~B}, \mathrm{C}, \mathrm{D}, \mathrm{E}, \mathrm{F}, \mathrm{G}, \mathrm{H}, \mathrm{I}$ & 3 & 3 & 3 & 5 \\
$\mathrm{PQ} 4$ & $(0 / 90 / \pm 45)_{\mathrm{s}}$ & 4 & $\mathrm{~A}, \mathrm{~B}, \mathrm{C}, \mathrm{D}, \mathrm{E}, \mathrm{F}, \mathrm{G}, \mathrm{H}, \mathrm{I}$ & 3 & 3 & 3 & 5 \\
\hline
\end{tabular}


where $P_{\max }$ and $A_{\text {net }}$ are the maximum load at failure and net-sectional area of composite plate respectively. $A_{n e t}$ is given as the gross plate cross-sectional area minus sum of plate thickness, $t$ and hole size, $d$, mathematically express as $A_{n e t}=A_{\text {gross }}-n d t, n$ is sum of hole in a vertical line of load transfer. Mechanical testing of testing coupons was carried out under quasi-static tensile loading using an Instron Universal Testing Machine (UTM) with $50 \mathrm{kN}$ load cell and crosshead speed of $0.5 \mathrm{~mm} / \mathrm{min}$, following ASTM standard D3039. Load and displacement profiles were recorded at one-second intervals using PC data-logging package from Instron. Mechanical testing was performed to obtain peak load of all joint configurations tested from load-displacement profile.

\section{FINITE ELEMENT MODELLING}

\section{XFEM Modelling Approach}

Finite element modelling is carried out by implementing 2-D modelling framework using ABAQUS CAE Version 6.13. Extended Finite Element Method (XFEM) was introduced by Moës et al. [7] and extended from classical finite element expression which has enriched function to enable the crack be tracked visually. XFEM implemented physically constitutive model which is based on traction-separation relationship to predict the notched strength of composite plates. The XFEM formulation is an extension to conventional FEA which is based on the integration of an enriched function with additional degrees of freedom but retaining properties such as sparsity and symmetry. This enriched function consists of near-tip asymptotic function to captured singularity around the crack-tip and a discontinuity function that allows modelling of the displacement jump between crack faces during crack propagation.

Table 2. Elastic and materials properties used in current work.

\begin{tabular}{ccccccc}
\hline \multirow{2}{*}{$\begin{array}{c}\text { Lay-up } \\
\text { types }\end{array}$} & \multicolumn{3}{c}{ In-plane elastic properties } & \multicolumn{2}{c}{ Material properties } \\
\cline { 2 - 7 } & $\boldsymbol{E}_{\boldsymbol{x}}(\mathbf{M P a})$ & $\boldsymbol{E}_{\mathbf{y}}(\mathbf{M P a})$ & $\boldsymbol{v}_{\boldsymbol{x} \boldsymbol{y}}$ & $\begin{array}{c}\boldsymbol{G}_{\boldsymbol{x} \boldsymbol{y}} \\
(\mathbf{G P a})\end{array}$ & $\boldsymbol{\sigma}_{\boldsymbol{o}}(\mathbf{M P a})$ & $\boldsymbol{G}_{\boldsymbol{c}}\left(\mathbf{k J} / \mathbf{m}^{\mathbf{2}}\right)$ \\
\hline PX2 & 2260.33 & 2260.33 & 0.07 & 198.23 & 54.70 & 5.3 \\
PX4 & 2291.04 & 2291.04 & 0.09 & 200.92 & 55.47 & 10.5 \\
PQ4 & 2008.93 & 2008.93 & 0.33 & 755.23 & 50.78 & 7.75 \\
\hline
\end{tabular}

A simplified 2-D modelling is required to achieve faster convergence without sacrificing physical representation as 3-D modelling framework is highly time- and cost-consuming which leads to convergence difficulties. Elastic properties comprised of in-plane tensile modulus, $\left(E_{x} / E_{y}\right)$, shear modulus, $G_{x y}$ and Poisson's ratio, $v_{x y}$ of WKRP used in the current work were measured from experimental set-up following ASTM standard D3039. These elastic properties regarded as "smeared-out" properties as given in Table 2. The description on fabrication process and mechanical testing were given in previous work [8]. The material properties used in constitutive model (i.e., unnotched strength, $\sigma_{o}$ and fracture energy, $G_{c}$ ) were determined from independently laboratory testing [9].

All multi-holes configurations are symmetrical in y-axis and hence idealized as half-model to save computational cost and time effort. However, in some staggered multi-hole configurations (i.e., configuration $\mathrm{F}$ and $\mathrm{H}$ ) are made full model as no 
symmetry in y-axis. Figure 2(a) shows the meshing refinement at the vicinity of hole edge as stress are concentrated in this region and the mesh in remaining plate regions were made coarser to allow for effective computation. Coupling constraint was assigned at the surface B to follow a reference point which has been set as applied displacement as illustrated in Figure 2(b). The boundary condition and applied loading were properly assigned according to mechanical testing condition, where displacement was assigned on the right edge and fixed boundary was assigned on the left edge. First-order plane stress element with element designation code of CPS4 was used as element type.

(a)

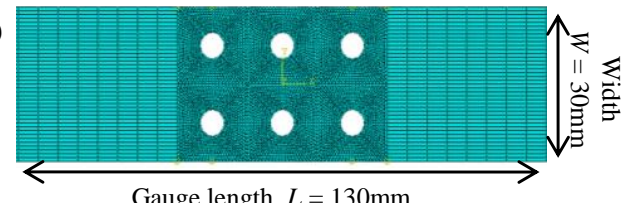

(b)

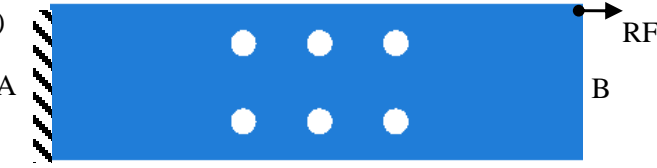

Figure 2. (a) Meshing of multi-holes FEA model (b) Loading and boundary conditions.

\section{Sensitivity Study}

Two parametric studies were carried out to assure the strength prediction result in current work is free from any variables. First parametric study is to determine an acceptable damage stabilization coefficient value to ensure the strength prediction results were independent from viscosity parameter. If the viscosity implemented is relatively small, it is difficult to obtain good converged solutions. However, high viscosity values gave excessive and non-physical results in XFEM strength prediction work (but easy to obtain convergence). The damage stabilization value used in further XFEM modelling work is kept constant of $1 \times 10^{-5}$ as shown in Figure 3(a). This value was adopted from sensitivity study that showed value consistency smaller than $1 \times 10^{-5}$.

(a)

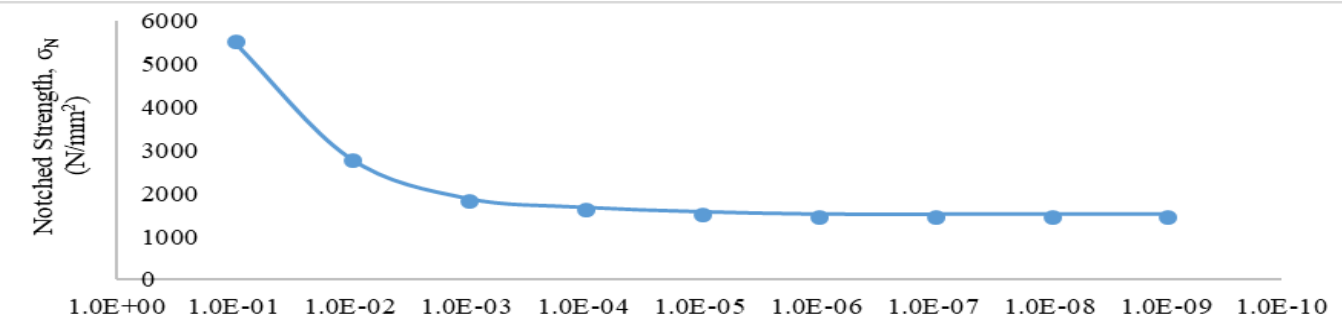

Damage Stabilization Coefficient

(b)

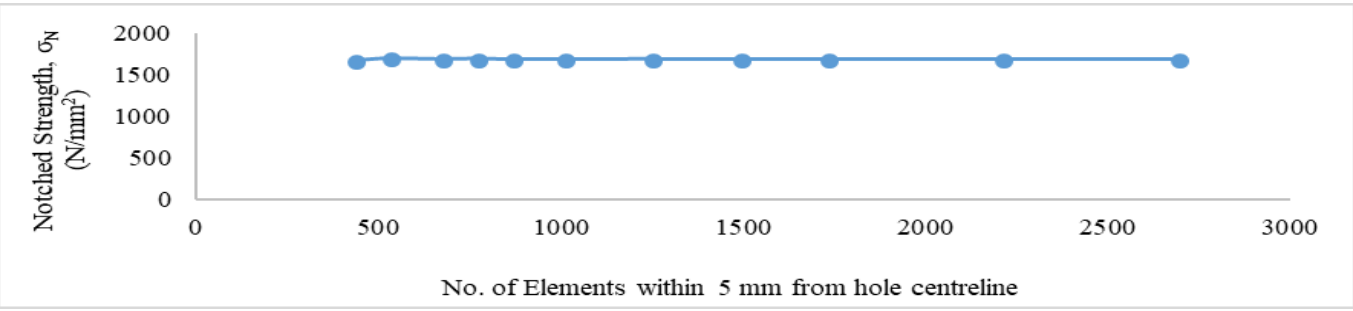

Figure 3. Sensitivity study of notched strength in PX2 Configuration B as a function of (a) damage stabilization coefficient (b) mesh refinement.

Figure 3(b) shows sensitivity study on mesh refinement of PX2 lay-up in Configuration B. The mesh refinement is limited within $5 \mathrm{~mm}$ radius from hole centreline, and similar mesh refinements were made to the other two holes. As shown in 
Figure 3(b), XFEM strength prediction is insensitive to mesh refinement at the vicinity of the crack tip as the stress field is driven by energetic approach. This is in contrast with the classical finite element modelling as highly mesh refinement is required at the notch tip due to singularity stress exhibited at the sharp crack tip.

\section{RESULTS AND DISCUSSIONS}

\section{Experimental Results}

Figure 4 shows experimental observation of staggered and non-staggered configurations under quasi-static tensile loading using an Instron Universal Testing Machine (UTM) at Structure Laboratory, Universiti Tun Hussein Onn Malaysia (UTHM). All testing coupons were showing net-tension failures along net-sectional plane associated with stress raisers, non-staggered configurations exhibited failure path across the outermost holes and staggered configurations demonstrated failure path across with maximum sum of hole sectional areas in vertical line perpendicular to applied loading direction.

Contradictory to Cunningham et al. [5] work, staggered configurations showed 'zig-zag' failure in testing coupons with smaller pitch distance. Staggered configurations in GFRP demonstrates various failure modes dependent upon variables such as pitch and gage distance, and hole arrangement. Non-staggered counterparts from Cunningham's work showed similar failure path as observed in current work. On the contrary, due to low modulus in WKRP may exhibit only shortest damage path across the plate width. However, their work is based on unidirectional glass fiber reinforced polymer (GFRP) composite plates. The microscopic work is out of the scope in current work, however, it is expected that the presence of high crimping region in plain weave architectures tends to prevent crack to move diagonally.
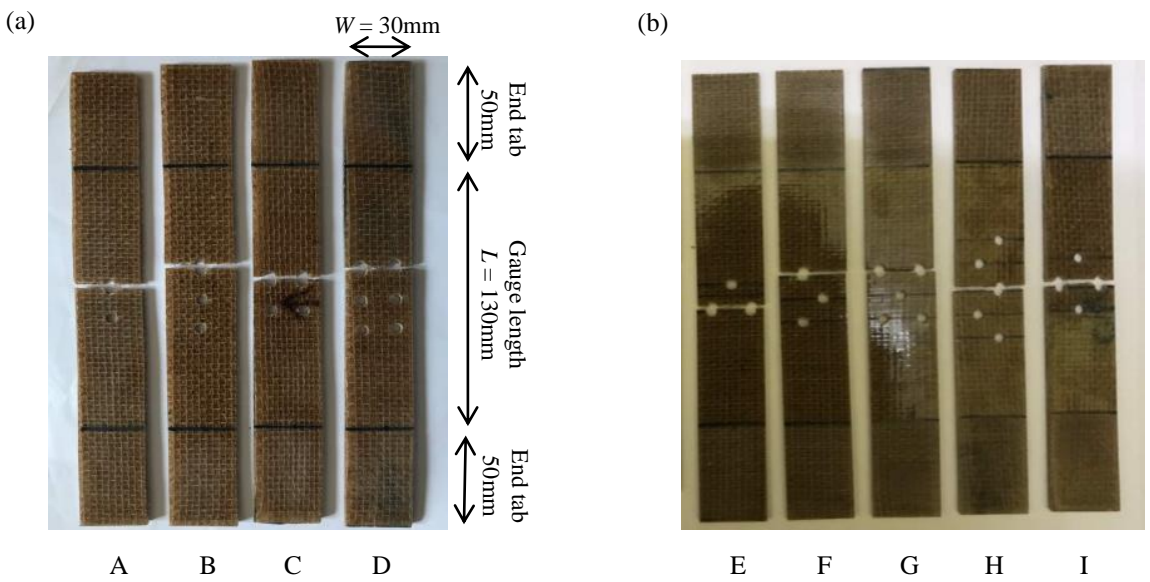

Figure 4. Failed testing coupons in (a) non-staggered series (b) staggered series.

Figure 5 gives peak load in load displacement profile from data-logger conducted experimentally. Theoretically, larger net-sectional area of composite plate gives larger resistance to applied load (hence higher peak load). As described previously, larger sum of hole sectional area in a vertical line demonstrates lower peak load, more significantly in staggered hole configurations. In non-staggered hole series, single-row (A and B) gives higher peak load than double-row (C and D) as a results of smaller net sectional area in single-row case. Nevertheless, configuration A and B does 
not show significant difference as both configurations have similar net-sectional area regardless to number of holes in a particular row.

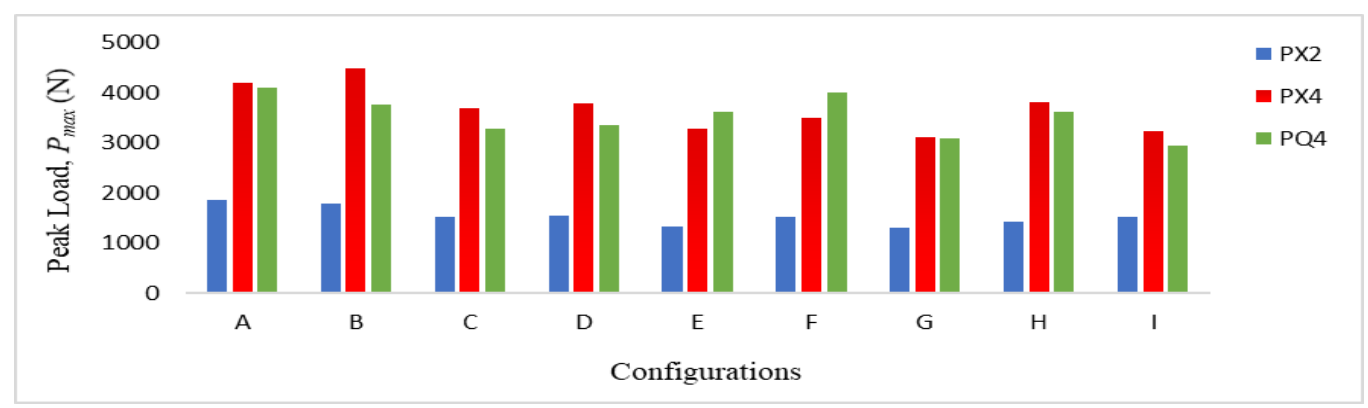

Figure 5. Experimental peak load in all configurations investigated.

In staggered series, configuration $\mathrm{E}, \mathrm{G}$ and I gives the least notched strength compared to other series due to smallest net-sectional area and failure is more likely to occur across two holes along net-section plane perpendicularly to applied loading. Higher failure load in configuration $\mathrm{H}$ is much expected as it able to perform larger elastic hole elongation due to higher number of holes compared to other staggered series. Kolasangiani et al. [10] conducted notched steel plate with various sizes of holes and found that increases of number and diameter of holes were increased the steel plate strain, thereby increasing plate strength. Eugene et al. [11] concludes that low notched strength in staggered series is due to extensive fibre breakages as a result of highest maximum stress value compared to other non-staggered counterparts.

Comparison with series of similar plate thickness, PX4 lay-ups gives relatively higher notched strength than PQ4 lay-ups due to the larger volume $0^{\circ}$ fibre direction in cross-ply lay-ups. This is because $0^{\circ}$ fibre direction is the optimum angle to resist tensile loading applied. Furthermore, comparison with similar lay-up types, thicker layup, PX4 gives larger peak load than thinner plates, PX2 (notched strength is also higher in PX4). This may due to larger inter-facial strength in thicker plates between adjacent layers prior to delamination.

\section{Validation of FEA Results}

Table 3 shows comparison of experimental results and strength prediction in 2-D modelling conducted in all testing series. Current finite element modelling approach used independently measured elastic and material values from experimental set-up. From experimental observations, self-similar failure was exhibited through the plate thickness. Elastic and materials properties implemented within FEA modelling framework were considered as smeared-out properties due to self-similar failure behaviour. Overall, it was found that all testing series produced good agreement of less than $11 \%$ discrepancy (some configurations series gave less than 5\%). 
Table 3. Comparison of notched strength between experimental datasets and finite element modelling.

\begin{tabular}{|c|c|c|c|c|c|c|c|c|c|c|}
\hline \multirow{2}{*}{$\begin{array}{l}\text { Lay- } \\
\text { up }\end{array}$} & \multirow{2}{*}{ Configuration } & \multicolumn{4}{|c|}{ Non-staggered } & \multicolumn{5}{|c|}{ Staggered } \\
\hline & & $\mathbf{A}$ & $\mathbf{B}$ & $\mathbf{C}$ & D & $\mathbf{E}$ & $\mathbf{F}$ & $\mathbf{G}$ & $\mathbf{H}$ & $\mathbf{I}$ \\
\hline \multirow{3}{*}{$\mathrm{PX} 2$} & Experimental $\left(\mathrm{N} / \mathrm{mm}^{2}\right)$ & 35.5 & 33.7 & 35.7 & 35.2 & 43.1 & 33.0 & 39.6 & 34.3 & 44.3 \\
\hline & 2-D modelling $\left(\mathrm{N} / \mathrm{mm}^{2}\right)$ & 31.7 & 31.6 & 37.9 & 37.1 & 44.1 & 34.5 & 40.2 & 35.0 & 44.5 \\
\hline & Error $(\%)$ & -10.6 & -6.4 & 6.3 & 5.6 & 2.5 & 4.5 & 1.5 & 2.0 & 0.01 \\
\hline \multirow{3}{*}{ PX4 } & Experimental $\left(\mathrm{N} / \mathrm{mm}^{2}\right)$ & 39.9 & 40.8 & 44.0 & 43.2 & 52.1 & 41.8 & 51.5 & 46.7 & 51.2 \\
\hline & 2-D modelling $\left(\mathrm{N} / \mathrm{mm}^{2}\right)$ & 39.2 & 39.2 & 43.0 & 42.6 & 51.5 & 42.8 & 55.5 & 45.4 & 54.6 \\
\hline & Error $(\%)$ & -1.8 & -3.9 & -2.3 & -1.4 & -1.1 & 2.2 & 7.8 & -2.7 & 6.5 \\
\hline \multirow{3}{*}{ PQ4 } & Experimental $\left(\mathrm{N} / \mathrm{mm}^{2}\right)$ & 37.3 & 34.7 & 40.2 & 40.0 & 54.5 & 46.2 & 50.2 & 41.9 & 48.1 \\
\hline & 2-D modelling $\left(\mathrm{N} / \mathrm{mm}^{2}\right)$ & 38.7 & 38.1 & 42.9 & 44.3 & 56.1 & 44.7 & 54.7 & 45.2 & 48.4 \\
\hline & Error (\%) & 3.7 & 9.6 & 6.6 & 10.9 & 3.1 & -3.3 & 8.9 & 8.0 & 0.01 \\
\hline
\end{tabular}

In multi-holes arrangement, staggered holes produced better notched strength predictions (less than 5\%) than non-staggered holes. It is expected that due to staggered hole arrangement, hole elongations are more representative in FEA modelling as pitch distance in longitudinal direction is larger than non-staggered that allow better modelling of elastic deformation within pitch adjacent holes and at hole vicinity.

In variation to plate thickness, thicker plates, PX4 gives better agreement to experimental results (less than 8\% discrepancy) than PX2 lay-ups counterparts. Similar finding was found in Supar \& Ahmad [6] where better strength prediction in thicker unidirectional GFRP plates. Composite materials comprised of different stacking orientation layers, current approach implemented smeared-out properties which is more representative in thicker plates, therefore better strength prediction in cross-ply lay-ups is not surprising. In comparison to lay-up types, cross-ply series gave best prediction than quasi-isotropic lay-ups. This may due to the existence of shear coupling terms $\left( \pm 45^{\circ}\right)$ fibre orientation may not well modelled in current XFEM framework.

\section{CONCLUSIONS}

Experimental framework and 2-D XFEM strength prediction modelling has been carried out with variation of lay-up types, plate thickness and multi-holes configurations as specified in the testing series. Net-tension failure mode occurred in all testing series investigated. Crack is initiated and propagated in self-similar manner through the plate thickness across net-tensional plane. A simplistic 2-D modelling implemented physically-based traction-separation relationship as constitutive models, current work used independently measured material properties. Good agreement of notched strength between experimental results and finite element modelling was found in all testing series with less than $11 \%$ discrepancy. Better notched strength predictions were found in testing series with staggered hole configurations, cross-ply lay-ups and thicker plates. This work can be further improved by implementing 3-D modelling framework by explicitly includes bolt load, friction load, surface interactions and secondary bending effect. Due to emerging computing technology, material designer able to predict the strength of engineering materials by using numerical approaches. 


\section{ACKNOWLEDGEMENTS}

The author would like to thank Universiti Tun Hussein Onn Malaysia (Vot. U549) in providing financial support for this project work.

\section{REFERENCES}

[1] Saba N, Paridah MT \& Jawaid M. Mechanical properties of kenaf fibre reinforced polymer composite. A review, Construction and Building Materials. 2015;76:87-96.

[2] Laurin F, Julien C \& Paulmier P. Damage and strength analysis of open-hole laminated plates under tensile, compressive and bending loadings. 17th European Conference on Composite Materials (Munich, Germany). 2016;1-8.

[3] Sun Y, Hu W, Shen F, Meng Q \& Xu Y. Numerical simulations of the fatigue damage evolution at a fastener hole treated by cold expansion or with interference fit pin. International Journal of Mechanical Sciences. 2016;107:188200.

[4] $\mathrm{Lu} \mathrm{A}, \mathrm{Xu} \mathrm{Z} \&$ Zhang N. Stress analytical solution for an infinite plane containing two holes. International Journal of Mechanical Sciences. 2017;128129:224-234.

[5] Cunningham D, Harries KA \& Bell AJ. Open-hole tension capacity of pultruded GFRP having staggered hole arrangement. Engineering Structures. 2015;95:815.

[6] Supar K \& Ahmad H. XFEM modelling of multi-holes plate with single-row and staggered holes configurations. MATEC Web of Conferences. 2017;103:1-8.

[7] Moës N, Dolbow J \& Belytschko T. A finite element method for crack growth without remeshing. International Journal for Numerical Methods in Engineering. 1999;46:131-150.

[8] Supar K \& Ahmad H. Stress Distribution Study on Multi-holes Configurations in Woven Fabric Kenaf Composite Plates. IOP Conference Series: Materials Science and Engineering. 2017;271:1-8.

[9] Ahmad H. Stress distribution of bolted joints with different lay-up types. MATEC Web of Conferences. 2016; 74:1-9.

[10] Kolasangiani K, Farhangdoost K, Shariati M \& Farahani AV. Ratcheting assessment of notched steel samples subjected to asymmetric loading cycles through coupled kinematic hardening-neuber rules. International Journal of Mechanical Sciences. 2018. In Press, Accepted Manuscript.

[11] Eugene DJ, Russel K, Wen SC \& Selvaraj S. Strength of composite laminate with multiple holes. University of Texas at Arlington, The Boeing Company. 2009; 1-9. 